\title{
Buen gobierno (Altos cargos) Good governance (Senior government officials)
}

\author{
Antonio Descalzo González \\ Universidad Carlos III de Madrid \\ ORCID ID 0000-0002-2764-5533 \\ antonio.descalzo@uc3m.es
}

\section{Cita recomendada:}

Descalzo González, A. (2020). Buen gobierno (Altos cargos). Eunomía. Revista en Cultura de la Legalidad, 18, pp 239-257.

doi: https://doi.org/10.20318/eunomia.2020.5275

Recibido / received: 05/02/2020

Aceptado / accepted: 03/03/2020

\section{Resumen}

En este trabajo se identifica el buen gobierno con el estatuto jurídico aplicable a los altos cargos de la Administración Pública. En cuanto personas que acceden y desempeñan tareas públicas conforme al principio de confianza política su régimen se caracteriza, conforme a la legislación vigente objeto de examen, por un sistema dominado por los principios de integridad, transparencia y responsabilidad ${ }^{1}$.

\section{Palabras clave}

Organización pública, buen gobierno, altos cargos, integridad, transparencia, responsabilidad.

\begin{abstract}
This work identifies good governance with the legal status of government senior officials. These are people that hold public positions through political appointment, so their legal status is based in the principles of integrity, transparency and accountability, according to the current legislation.
\end{abstract}

\section{Keywords}

Administrative organizational structure, good governance, senior officials, integrity, transparency, accountability.

\footnotetext{
${ }^{1}$ Abreviaturas utilizadas: AGE: Administración General del Estado. CE: Constitución española de 1978. CNMC: Comisión Nacional de los Mercados y de la Competencia. EBEP: Real Decreto Legislativo $5 / 2015$, de 30 de octubre, por el que se aprueba el texto refundido de la Ley del Estatuto Básico del Empleado Público. LG: Ley 50/1997, 27 de noviembre, del Gobierno. LOEPSF: Ley Orgánica 2/2012, de 27 de abril, de Estabilidad Presupuestaria y Sostenibilidad Financiera. LOFAGE: Ley 6/1997, de 14 de abril, de organización y funcionamiento de la Administración General del Estado. LRAC: Ley 3/2015, de 30 de marzo, reguladora del ejercicio del alto cargo de la Administración General del Estado. LRJSP: Ley 40/2015, de 1 de octubre, de régimen jurídico del sector público LRJPAC: Ley 30/1992, de 26 de noviembre, de régimen jurídico de las Administraciones públicas y del procedimiento administrativo común. LTBG: Ley 19/2013, de 9 de diciembre, de transparencia, acceso a la información y buen gobierno.
} 
SUMARIO. 1. El buen gobierno en el marco del derecho de la organización. 2. Buen gobierno, gobernanza y buena administración. 3. El ámbito subjetivo del buen gobierno. 4. La separación disciplinaria en materia de buen gobierno. 5. Conclusiones. 6. Bibliografía.

\section{El buen gobierno en el marco del derecho de la organización}

La preocupación por el buen y recto ejercicio del poder público no es cosa nueva en nuestro derecho. En línea con las fuentes del derecho romano tardío, las Partidas establecieron el llamado «juicio de residencia» o "residencia» "como procedimiento por el cual se revisaba la actuación de algunos oficiales reales tras su cese, y se determinaba y exigía la responsabilidad en que eventualmente hubieren incurrido por los actos realizados en el ejercicio de sus cargos» (González, 1978, p. 193). Esta técnica de control, junto con la toma de cuentas y las pesquisas, se aplicó, con altibajos según las épocas (González, 2000, pp. 253-254), desde el reinado de Alfonso XI hasta la llegada de los Reyes Católicos, quienes, sin perjuicio de las anteriores, establecieron en la ley 60 del Ordenamiento de Toledo de 1480 la llamada «visita». Esta consistía en "una pesquisa general ordenada por el rey sobre el estado de tal o cual tierra, a cuyo agente -el visitador- se concede el poder coercitivo necesario para controlar la conducta de los oficiales públicos e imponer los mandamientos que dicte con el objeto de favorecer el cumplimiento del Derecho» (Garriga, 1991, p. 226) $)^{2}$. A su vez, y en paralelo con lo anterior, la atención de nuestro derecho histórico por las cualidades y aptitudes que deben reunir los responsables públicos también es muy antigua y pródiga en ejemplos ${ }^{3}$ conforme acredita, por todas, la regla establecida en el libro 2, título 8, Ley 1 de las Ordenanzas Reales de Castilla, según la cual «conviene que el Chanciller sea hombre muy fiel, honrado, de verdad, convenible y de conciencia, y sabio en su Oficio cumplido, y saviamente, y sea hombre liberal».

La relación entre conducta ejemplar de las autoridades y el buen gobierno de las organizaciones públicas viene, por tanto, muy de lejos. Así lo testimonia de manera excelente la conocida descripción ${ }^{4}$ que hiciera en su día el profesor García Pelayo de la imagen del buen gobierno que ofrece el fresco del Palazzo Comunale de Siena, obra del siglo XIV de Ambrogio Lorenzetti, al decir que:

la justicia, iluminada por la sabiduría, integra a los hombres en la concordia, y desde ella en la corporación o cuerpo místico de la comuna bajo el gobierno impersonal y abstracto del bien común, el cual, constantemente inspirado por las virtudes políticas, asegura un orden pacífico del que se excluye toda violencia, salvo a los malhechores, obtiene sin presión los impuestos de los ciudadanos y la sumisión de los señores del campo (García-Pelayo, 2009, p. 1239).

Sin afán exhaustivo, esa misma relación aparece, por ejemplo, en la Constitución de Cádiz de 1812, al señalar en su artículo 241 que «los consejeros de Estado, al tomar posesión de sus plazas, harán en manos del Rey juramento de guardar la Constitución, ser fieles al Rey, y aconsejarle lo que entendieren ser

\footnotetext{
2 Sobre la importancia de tales técnicas para la explicación de los actuales mecanismos de información, conocimiento y fiscalización (Parejo, 2016).

3 Una exposición sistemática de las reglas del derecho histórico dedicadas a los agentes públicos puede verse en (Nieto, 1960).

${ }^{4}$ Al respecto véase: Fernández (2007); Bassols (2015), y Castillo (2015).
} 
conducente al bien de la Nación, sin mira particular ni interés privado». Del mismo modo, dentro del Consejo de Estado la preocupación por la recta actuación de sus miembros era ya sentida en épocas anteriores, pues, como resalta J. H. Elliot, «los consejeros eran plenamente conscientes de la importancia de la reputación (de no desprestigiarse) y el concepto era fundamental en la toma de decisiones de política exterior en la España de los siglos XVI y XVII» (Elliot, 2012, p. 124). Y, desde luego, esa apelación al gobierno impersonal y abstracto del bien común, constantemente inspirado por las virtudes políticas, donde no cabe que los responsables públicos miren al interés privado, aparece claramente dibujada tanto para los miembros del Gobierno como para el personal de la Administración Pública según disponen, respectivamente, los artículos 98.3 y 4 y 103.3 de la actual Constitución.

En realidad, como adelantó Eduardo García de Enterría, el problema básico de la organización es:

el de la articulación de un grupo de seres personales, cada uno con su órbita propia de intereses y de tendencias, en el marco abstracto e impersonal de la organización a la cual deben servir, organización que, por otra parte, no puede existir sin que ese grupo de hombres le presten su propia fuerza espiritual, siempre potencialmente disociadora (García De Enterría, 1985, p. 106).

Colocados en este sumario contexto, puede decirse que el bloque normativo formado actualmente por la Ley 19/2013, de 9 de diciembre, de transparencia, acceso a la información y buen gobierno (LTBG), y las más recientes leyes $3 / 2015$, de 30 de marzo, reguladora del ejercicio del alto cargo de la Administración General del Estado (LRAC), y 40/2015, de 1 de octubre, de régimen jurídico del sector público (LRJSP), junto con las modificaciones introducidas por ésta última en la anterior Ley 50/1997, 27 de noviembre, del Gobierno (LG), no son otra cosa que un nuevo eslabón en una larga cadena dedicada al buen gobierno en la cosa pública.

Ello no obstante, puede quizás notarse que aportan, sobre la base principal del régimen jurídico aplicable a los llamados altos cargos, la novedad de introducir dentro del derecho de la organización algunas de las principales tendencias que alimentan el diseño interno de las instituciones públicas bajo esa rúbrica general del llamado buen gobierno ${ }^{5}$. Dar cuenta de este perfil del derecho de la organización constituye el objeto de esta voz sobre la base, particularmente, del régimen establecido en la legislación recién citada.

Sin embargo, conviene antes advertir que algunos de los criterios generales que hoy se imponen en nuestras Administraciones públicas en este terreno estaban incluidos entre los principios establecidos en el artículo 3 de la derogada Ley 6/1997, de 14 de abril, de organización y funcionamiento de la Administración General del Estado (LOFAGE). Del mismo modo, incluso antes, en el artículo 3 de la también derogada Ley 30/1992, de 26 de noviembre, de régimen jurídico de las Administraciones públicas y del procedimiento administrativo común (LRJPAC) ${ }^{6}$, aunque, seguramente, hasta el momento no se habían traducido en medidas concretas capaces de ordenar y disciplinar el ámbito de la organización y

\footnotetext{
${ }^{5}$ Al respecto, Ramió señala que hay unanimidad en el diagnóstico y también en las propuestas: «más transparencia, más información (y no tanto márketing político e institucional), más rendición de cuentas (en especial en el aspecto económico), más evaluación de políticas públicas, diseños organizativos más fluidos y menos burocráticos, una función pública más racional» (2016, p. 68).

${ }^{6}$ Pues los principios de transparencia y participación a los que concretamente nos referimos luego fueron incorporados a la LRJPAC, con ocasión de la modificación operada en su interior por la Ley 4/1999, de 13 de enero.
} 
funcionamiento interior de la Administración Pública desde el parámetro actual del buen gobierno ${ }^{7}$.

Llama igualmente la atención, no obstante, que la vigente normativa en esta materia del buen gobierno no haga una mención expresa a la norma fundamental a la hora de «establecer las obligaciones de buen gobierno que deben cumplir los responsables públicos así como las consecuencias derivadas de su incumplimiento» (artículo 1 LTBG). Pues, en efecto, basta reparar en el Título V de la Constitución, dedicado a las relaciones entre el Gobierno y las Cortes Generales, para comprobar que su hilo conductor consiste en establecer técnicas de transparencia, control y rendición de cuentas sobre el Gobierno y sus miembros. Y, de la misma manera, procede constatar que una buena parte del contenido del buen gobierno establecido en el indicado bloque encabezado por la LTBG se cifra, como digo, en un catálogo de infracciones y sanciones en materia de incompatibilidades y conflictos de intereses que traen causa, como se sabe, del artículo 98.4 de la norma constitucional.

Con todo, quizás resulta más llamativo que este bloque normativo no mencione como causa eficiente de su elaboración el clima social de claro malestar cuando no de crispación- por los casos de mala o deficiente gestión ${ }^{8}$ detectados en el funcionamiento de los poderes públicos alrededor, principalmente, del urbanismo, los contratos del sector público y las ayudas públicas y, por tanto, la necesidad de establecer instrumentos jurídicos para prevenir y poner fin a tan penosa situación ${ }^{9}$. Esta relación es, sin embargo, indiscutible como demuestran la relevancia otorgada al valor de la integridad personal en los textos legales -en la exposición de motivos de la LTBG se recalca la idea de que las autoridades «deben ser un modelo de ejemplaridad en su conducta»- y, a su vez, la visible exigencia de la sociedad de dar rápida respuesta a los supuestos de corrupción que, en rigor, han traspasado muy de largo el terreno aludido del urbanismo para penetrar de lleno en una gran parte de la vida pública española ${ }^{10}$.

\footnotetext{
${ }^{7}$ Circunstancia que viene de lejos como testimonia Nieto, al referir que el derecho administrativo enseña «como puede defenderse el ciudadano contra las agresiones del Poder público; pero nada, o casi nada, le dice sobre cómo tiene que actuar la Administración para ser mínimamente eficiente y para responder de manera eficaz a las exigencias sociales» (1984, p. 10).

${ }^{8}$ En relación con el concepto de mala gestión pública, el artículo 228 del Tratado de Funcionamiento de la Unión Europea (TFUE), señala que el Parlamento Europeo elegirá a un Defensor del Pueblo que conocerá de reclamaciones «relativas a casos de mala administración en la acción de las instituciones, órganos u organismos de la Unión», entre los que se incluyen, las irregularidades administrativas, la injusticia y el abuso de abuso de poder. Y, en directa relación, el artículo 43 de la Carta de los Derechos Fundamentales de la Unión Europea (2000/C 364/01), dispone luego que «todo ciudadano de la Unión o toda persona física o jurídica que resida o tenga su domicilio social en un Estado miembro tiene derecho a someter al Defensor del Pueblo de la Unión los casos de mala administración en la acción de las instituciones u órganos comunitarios, con exclusión del Tribunal de Justicia y del Tribunal de Primera Instancia en el ejercicio de sus funciones jurisdiccionales». En el derecho interno tales reglas enlazan, como se sabe, con la figura del Defensor del Pueblo, pues, aunque no se utiliza de manera expresa la noción de mala administración, el artículo 1 de la Ley orgánica 3/1981, de 6 de abril, del Defensor del Pueblo, establece que «es el alto comisionado de las Cortes Generales designado por éstas para la defensa de los derechos comprendidos en el Título I de la Constitución, a cuyo efecto podrá supervisar la actividad de la Administración, dando cuenta a las Cortes Generales» y, en ejercicio de tal cometido, «podrá iniciar y proseguir de oficio o a petición de parte, cualquier investigación conducente al esclarecimiento de los actos y resoluciones de la Administración pública y sus agentes, en relación con los ciudadanos, a la luz de lo dispuesto en el artículo ciento tres, uno, de la Constitución, y el respeto debido a los Derechos proclamados en su Título primero».

${ }^{9}$ Sobre las causas y respuestas a la corrupción urbanística véase: Menéndez (2008); Iglesias (2007); Parejo (2007), y Parejo (2013).

${ }^{10}$ Véase al respecto, con amplia bibliografía: Villoria e Izquierdo (2016) y Ponce (2012, pp. 93-140); aunque no puede olvidarse que el fenómeno de la corrupción pública fue denunciado hace ya tiempo por Nieto (1997).
} 
No por azar, también en el marco general de la Unión Europea se había detectado esa necesidad de luchar contra los casos de mala gestión pública vinculados a la actuación personal de los altos responsables y, por tanto, de establecer medidas bajo la idea común del buen gobierno. Así, el Informe del comité de expertos independientes sobre presuntos casos de fraude, mala gestión y nepotismo en la Comisión Europea, de 15 de marzo de $1999^{11}$-que provocó, el mismo día de su publicación, la dimisión colectiva de los miembros de la Comisión presidida por Jacques Santer-, explica que si bien tales categorías de conceptos se superponen y no resulta siempre fácil su distinción en un caso determinado, sirven , no obstante, como indicadores de las normas de corrección que, por el contrario, deben cumplirse en el ejercicio de un cargo público de importancia. De esta suerte y, en ausencia en esa fecha de otras normas o códigos específicos de conducta, el Informe, en sus páginas 10 y 126, expresa que el comportamiento correcto de los cargos públicos exige una actuación independiente, íntegra y discreta al servicio del interés general y conforme con los principios de apertura, transparencia y responsabilidad; notas, todas ellas, que ahora se repiten hasta la saciedad para configurar este llamado buen gobierno.

En suma, la lucha contra las malas prácticas detectadas en el interior de las organizaciones públicas nutre y da sentido a la actual idea del buen gobierno en nuestro derecho al centrarse, tanto en la LTBG como en la LRAC, en un régimen jurídico dibujado por un conjunto de principios generales y de actuación aplicable a los miembros del Gobierno, a los altos cargos de la Administración General, así como a otras autoridades públicas asimiladas a las anteriores de las Comunidades Autónomas y de las Entidades Locales en virtud de la LTBG.

\section{Buen gobierno, gobernanza y buena administración}

Sobre la base de cifrar el buen gobierno en un régimen referido sólo a las personas que ocupan los altos cargos de dirección de las organizaciones públicas, el buen gobierno establecido en la LTBG se concreta, principalmente, en un derecho disciplinario -inspirado en su interpretación y aplicación por esos principios generales y de actuación-, al que se suma luego un doble régimen sancionador dedicado, uno, a la gestión económico-presupuestaria y, otro, a los conflictos de intereses en que pueden incurrir dichos responsables públicos. En lo que aquí interesa, este concreto régimen sancionador en materia de conflictos de intereses y de incompatibilidades se remite a la vigente LRAC.

La decisión de la LTBG de identificar el buen gobierno con un código de conducta para los dirigentes públicos de naturaleza esencialmente sancionadora, supone, en primer lugar, adoptar una interpretación reducida dentro de los posibles significados que rodean hoy a la noción de buen gobierno (Fernández, 2007)12 y que han llevado a encuadrarlo, bien dentro de la llamada nueva gestión pública, bien en el marco de la denominada gobernanza ${ }^{13}$, bien, en fin, en el derecho a una buena

\footnotetext{
${ }^{11}$ Anterior, por tanto, al Libro Blanco de la Comisión sobre la Gobernanza Europea (Bruselas, 25.7.2001 COM [2001] 428 final), donde los cambios propuestos para la entera Unión pasan por las mismas reglas principales de la apertura, la participación, la responsabilidad, la eficacia y la coherencia.

12 Villoria Mendieta e Izquierdo Sánchez consideran que «un buen gobierno sería, en definitiva, aquel que promueve instituciones formales (normas y reglamentos) e informales (lógicas de lo apropiado en cada organización pública) que fomentan la transparencia, la rendición de cuentas, la efectividad, la coherencia y la participación» y, más aun, la integridad y la objetividad en el servicio al interés general (2016, p. 344).

${ }^{13}$ El citado Libro Blanco elaborado por la Comisión Europea en el año 2001 identifica la gobernanza con las normas, procesos y comportamientos que influyen en el ejercicio de los poderes a nivel europeo, especialmente desde el punto de vista de la apertura, la participación, la responsabilidad, la eficacia y la coherencia.
} 
administración proclamado en el artículo 41 de la Carta de los Derechos Fundamentales de la Unión Europea (Carrillo, 2010, p.1138; Castillo, 2015, pp. 138143). Estos ámbitos, a su vez, coinciden en parte con el establecido para la buena gobernanza de los organismos reguladores o autoridades supervisoras donde la doctrina económica identifica el buen gobierno con los siguientes cuatro principios: independencia, rendición de cuentas, transparencia e integridad (Quintás, 2012, p. $54)$.

Así las cosas, el buen gobierno previsto en la LTBG establece las reglas de la relación de servicios que une a la persona física (titular o no del órgano) con la correspondiente Administración Pública ${ }^{14}$ y determina, por tanto, su integración en el derecho de la organización, al hacer operativos y aplicables una serie de principios centrales en todas las Administraciones públicas, a saber: la transparencia, la integridad y la rendición de cuentas.

La LTBG se coloca, entonces, en línea de continuación del conocido Informe Nolan, donde, como se sabe, se llama al altruismo, la integridad, la objetividad, la responsabilidad, la transparencia, la honestidad y el liderazgo de los responsables públicos en el ejercicio de su labor de gobierno y administración de las organizaciones ${ }^{15}$. Así mismo, se puede decir de forma más concreta, que tanto los principios generales y de actuación como las concretas infracciones disciplinarias que recoge la LTBG traen causa directa de las reglas previstas en el ya derogado Acuerdo del Consejo de Ministros, de 18 de febrero de 2005, aprobado mediante Orden número APU/516/2005, de 3 de marzo, por el que se aprueba el código de buen gobierno de los miembros del Gobierno y de los altos cargos de la Administración General del Estado; así como del posterior código de conducta de los empleados públicos, contenido en los artículos 53 a 54 del Real Decreto Legislativo 5/2015, de 30 de octubre, por el que se aprueba el texto refundido de la Ley del Estatuto Básico del Empleado Público (EBEP), aunque, como ya se ha insistido, nada se diga al respecto en la exposición de motivos de la $\mathrm{LTBG}^{16}$.

De esta manera y, como queda dicho, este amplio y complejo cuadro de valores predicable de los responsables públicos se contempla, en la LTBG, mediante la disposición de un vasto conjunto de principios generales y de actuación (artículo 26) cuya eficacia jurídica consiste en informar la interpretación y aplicación de un régimen sancionador (artículo 26.3) compuesto de tres piezas, a saber: un denominado régimen disciplinario (artículo 29), al que se suma, en segundo lugar, un sistema de infracciones y sanciones en materia de gestión económico-presupuestaria (artículo 28), derivado de la LOEPSF, así como, en fin, un sistema sancionador en materia de conflictos de intereses (artículo 27), previsto actualmente en la LRAC.

En suma, el buen gobierno que configura la LTBG parte de un conjunto de principios generales y de actuación para los responsables públicos que se traduce luego en un derecho sancionador que atiende a razones diversas.

Por de pronto, no cabe ninguna duda que las infracciones previstas en materia de gestión económico-presupuestaria obedecen a la lógica preocupación por la correcta utilización de los caudales públicos -la incursión en alcance o malversación

\footnotetext{
${ }^{14}$ Santamaría Pastor, observa que «relación de servicios es la del funcionario, pero también es la del ministro o la de cualquier otro cargo político o de confianza» (1984, p. 61).

15 Sobre el Informe Nolan véase: Martín-Retortillo (1997) y, más recientemente, Bustos Gisbert (2016).

${ }^{16}$ Puede, incluso, repararse en la clara cercanía que hay entre las razones de la Exposición de Motivos del EBEP para establecer su código de conducta y las contenidas en la de la LTBG para fundar el código de buen gobierno de los altos cargos. Sobre la relación entre ambas normas véase Bassols (2015, p. 41).
} 
en la administración de los fondos públicos es la primera de las infracciones- y, por tanto, enlazan sin dificultad con el valor de rectitud e integridad que identifica al buen gobierno, pero es igualmente cierto que restan cierta coherencia al código que quiere instaurarse. De un lado, por razones sistemáticas, ya que las conductas infractoras descritas están relacionadas con disposiciones presupuestarias concretas, por lo que parece más razonable que estuvieran en el texto legal correspondiente. De otra parte $\mathrm{y}$, principalmente, por el sentido último que quiere darse al buen gobierno. $\mathrm{Si}$, como dice la propia exposición de motivos, el buen gobierno responde a la idea de establecer «un modelo de ejemplaridad» para todos los responsables públicos, es evidente que debe nutrirse, como ya apuntaba el Informe Nolan, por una serie de valores o principios de carácter general, referidos a la integridad y rectitud personal de los cargos públicos, susceptibles de inspirar o guiar cualquier posible actuación de los mismos. No debería limitarse, por tanto, a realizar una detallada catalogación de conductas infractoras cuyo objetivo es prevenir y castigar la violación de ciertos mandatos normativos. Esa es la función reservada al derecho administrativo sancionador. Dicho de otra manera, no parece que deba identificarse el buen gobierno, sólo y exclusivamente, con el derecho disciplinario. Como ha señalado la doctrina para el caso específico de la función pública, la promoción de arquetipos éticos, enfatizando los valores y virtudes públicas, debe hacerse desde una óptica positiva que «incentive determinados comportamientos, si no mediante la gratificación económica, sí reconociendo a quienes demuestran una mejor predisposición al interés general y la mejora del servicio» (Rivero, 2012, p. 90).

En segundo lugar y, resaltando también la directa vinculación de la prevención de los conflictos de intereses con el valor de la integridad que caracteriza al buen gobierno, tampoco parece del todo acertada la decisión de la LTBG de incluir dentro del título del buen gobierno las «infracciones y sanciones en materia de conflicto de intereses», prevista en el artículo 27, a cuyo tenor:

el incumplimiento de las normas de incompatibilidades o de las que regulan las declaraciones que han de realizar las personas comprendidas en el ámbito de este Título será sancionado de conformidad con lo dispuesto en la normativa en materia de conflictos de intereses de la Administración General del Estado y para el resto de Administraciones de acuerdo con su propia normativa que resulte de aplicación.

Al margen del escaso valor de recordatorio que cabe otorgar al precepto, ya que es ciertamente obvio que la violación del régimen de conflictos de intereses debe ser sancionada, en su caso, conforme a la correspondiente ley aplicable, esta remisión insiste en identificar el buen gobierno sólo con infracciones concretas del ordenamiento. Es más, y en el extremo, este énfasis legal en la sola perspectiva sancionadora puede conducir a perder de vista el aspecto realmente decisivo del régimen sustantivo de los conflictos de intereses dentro del sistema de buen gobierno. Con ello, además, tampoco se gana aquí en coherencia, pues se mantiene la remisión a un texto legal -la LRAC- cuya regulación quiere integrarse en una suerte de nuevo estatuto personal de los altos cargos: el llamado buen gobierno.

Dicho de otra manera, en lugar de mantener la separación entre la LTBG y la más reciente LRAC, debería, quizás, haberse aprovechado la ocasión para dictar una regulación única.

Por último y, en tercer lugar, se llega al núcleo del buen gobierno dibujado por la LTBG, a saber: un derecho disciplinario (artículo 29) en cuya aplicación deben tenerse cuenta, fundamentalmente, los valores de integridad y rectitud contenidos en los principios generales y de actuación (artículo 26). 
Por consiguiente y, de acuerdo con todo lo anterior, puede decirse que la LTBG no asume el reto de establecer un completo estatuto de los responsables públicos donde, junto al régimen de acceso, permanencia y cese en el cargo, haya un sistema de derechos y obligaciones que detalle, por ejemplo, el sistema de retribución, el contenido y evaluación del desempeño, así como la rendición de cuentas; aspectos muy unidos, por cierto, al principio de transparencia que el Título I del texto normativo regula desde la óptica principal de la organización. Pues, en efecto, cabe advertir que una parte considerable del buen gobierno entendido en sentido amplio se refiere, precisamente, a la transparencia en todo lo relativo al ejercicio responsable de la actividad pública (Villoria, 2012).

Vale decir, por tanto, que la LRAC viene a completar en parte la codificación de obligaciones y derechos recogidos en la LTBG, así como a corregir algunas de las deficiencias apuntadas, toda vez que prevé, en particular: i) un régimen de nombramiento y ejercicio presidido, de nuevo, por el valor de la integridad personal, al exigirse, dentro de la idoneidad para el acceso a la condición de alto cargo, el requisito de la honorabilidad ${ }^{17}$ (artículo 2 LRAC); ii) un mayor control y publicidad de las declaraciones de bienes y derechos patrimoniales, y iii) la concreción vía presupuestaria de las retribuciones y de los gastos de representación (artículo 4 LRAC).

Además, junto con los principios ya previstos en la LTBG, la LRAC señala, ahora expresamente, que el ejercicio del alto cargo queda sometido especialmente a los de interés general, objetividad, austeridad, integridad, transparencia y responsabilidad (artículo 3 LRAC). Sin dejar nunca de lado la relevancia de los tres primeros en cuanto resulta incluso del entero sistema constitucional de la organización pública ex artículos 31.2, 103.1 y 135 CE, considero, como ya se apuntó más arriba, que los principios de integridad, transparencia y responsabilidad y/o rendición de cuentas son hoy los fundamentales en la configuración del buen gobierno como parte de la organización de las Administraciones públicas.

Al respecto y, en relación con la directa conexión entre transparencia e integridad, debe destacarse que una parte de la regulación de los conflictos de intereses, aspecto central en la configuración de la noción de alto cargo y del buen gobierno, tiene por objeto, justamente, la transparencia, al establecer el control, registro y publicidad de las actividades, bienes y derechos patrimoniales de los altos cargos (artículos 16, 17, 21, 22 y 23 LRAC) ${ }^{18}$.

Buena prueba de lo anterior es, asimismo, que en el artículo 8.1. f), g) y h) de la LTBG se impone la publicidad activa, a través de las sedes electrónicas o páginas web, de datos referidos a las retribuciones percibidas anualmente por los altos cargos, indemnizaciones por abandono del cargo, compatibilidad para el ejercicio de actividad privada al cese de alto cargo y, en fin, las declaraciones anuales de bienes y actividades de los representantes locales.

Por ello, insisto, no es casual que el primero de los principios generales del buen gobierno sea la «actuación con transparencia en la gestión de los asuntos

\footnotetext{
17 Sobre el origen y desarrollo de la regla de la honorabilidad como requisito para el acceso a cargos y actividades véase: Martín-Retortillo (1993) y, desde otra perspectiva, Bermejo Latre (2008).

${ }^{18}$ Regulación de las incompatibilidades y conflictos de intereses que, al mismo tiempo, enlaza con otro principio del buen gobierno que sanciona la CE de manera expresa como es el de la eficacia requerida en toda actuación de la Administración pública. El Tribunal Constitucional tiene perfectamente establecido su necesaria aplicación en esta materia en la Sentencia 178/1989, FJ 3.
} 
públicos», según indica el artículo 26.2.a). $1^{\circ}$ de la $L T B G^{19}$; y, en la misma línea, que el artículo 3.1d) de la LRAC destaque ahora la «transparencia y responsabilidad» como principios especialmente relevantes en el ejercicio del alto cargo.

El valor otorgado a la transparencia como técnica ligada a la integridad y a la responsabilidad y/o rendición de cuentas con la sociedad en el régimen de buen gobierno queda corroborado, en fin, cuando se observa que la primera sanción que en todo caso se impone para las infracciones muy graves y graves tanto en la LTBG como en la LRAC es la declaración del incumplimiento de la ley y su publicación en el «Boletín Oficial del Estado», o en el diario oficial que corresponda, una vez haya adquirido firmeza administrativa la resolución correspondiente (artículos 30 y 26 , respectivamente).

Sin embargo y, por desgracia, la LRAC no contiene avance significativo alguno respecto de la LTBG en el punto referido al contenido de un correcto sistema de evaluación del desempeño y de rendición de cuentas; pieza ciertamente fundamental para resolver con criterios seguros el cumplimiento de los principios que conforman el buen gobierno.

Es ciertamente llamativo que primero la LTBG y ahora la LRAC presten especial atención al plano final del derecho sancionador-siempre necesario en la ordenación de una materia o sector del ordenamiento-, pero desaprovechen la ocasión para disponer un completo estatuto personal de los responsables públicos.

Ello no obstante, y aunque sea de nuevo con cierta falta de rigor sistemático, el artículo 55.11 de la LRJSP establece para la Administración General del Estado una evaluación y rendición de cuentas, al ordenar que en el desempeño de sus funciones los titulares de los órganos superiores y directivos están sujetos: i) a responsabilidad profesional, personal y directa por la gestión desarrollada, y ii) al control y evaluación de la gestión por el órgano superior o directivo competente, sin perjuicio del control establecido por la Ley General Presupuestaria.

$Y$, en fin, puede notarse igualmente que la LRAC regula el régimen retributivo, de protección social y las compensaciones tras el cese para los altos cargos de la Administración General del Estado; regulación que enlaza con la reforma de las remuneraciones y limitación del número de los cargos públicos en las entidades locales ${ }^{20}$.

Supuesto todo esto anterior, procede detenerse a continuación en la delimitación del ámbito subjetivo de aplicación previsto para el buen gobierno en la LTBG.

\section{El ámbito subjetivo del buen gobierno}

Al respecto, es necesario reseñar que la amplia noción de los responsables públicos mencionada en el artículo 1 de la LTBG como personas obligadas a las reglas de

\footnotetext{
19 Aunque también es cierto que luego dice, de una manera un tanto contradictoria, que constituye infracción muy grave «la publicación o utilización indebida de la documentación o información a que tengan o hayan tenido acceso por razón de su cargo o función», conforme al artículo 29.1d) de la misma LTBG.

${ }^{20}$ La Ley de racionalización y sostenibilidad de la Administración Local introduce en la LBRL, un nuevo artículo 75 bis sobre el límite en el régimen retributivo de los miembros de las Corporaciones locales y del personal al servicio de las entidades locales, así como un nuevo artículo 75 ter sobre limitación en el número de los cargos públicos de las entidades locales con dedicación exclusiva.
} 
buen gobierno queda luego referida, en el artículo $25^{21}$, a la igualmente extensa de los altos cargos que, en rigor, no tiene tampoco contornos muy precisos en nuestro ordenamiento jurídico (Jiménez, 1998).

Dicho de otra manera, cuando el artículo 25 de la Ley apela a la amplia noción de alto cargo para su concreto objeto de "establecer las "obligaciones" de buen gobierno que deben cumplir los "responsables públicos" así como las consecuencias derivadas de su "incumplimiento"» (artículo 1, el subrayado es mío), se llega a situaciones de difícil encaje, como lo acredita, de manera notoria, que dicha noción del alto cargo comprenda no sólo a titulares de órganos, sino también a los «titulares de cualquier puesto de trabajo en el sector público estatal, cualquiera que sea su denominación, cuyo nombramiento se efectúe por el Consejo de Ministros, con excepción de aquéllos que tengan la consideración de subdirectores generales y asimilados» (artículo 1.2.g LRAC). Pues, de un lado, y conforme a los artículos 73 y 74 del EBEB, la noción de puesto de trabajo se vincula a la organización de la estructura interna de las Administraciones con el correlativo derecho de los empleados públicos al desempeño de los mismos. Y, de otra parte, los subdirectores generales no son nombrados ni cesados por el Consejo de Ministros (artículo 67.2 LRJSP). No parece, por tanto, que la figura del puesto de trabajo sea la adecuada para cerrar el largo elenco de los responsables públicos a los que se dirige las reglas de buen gobierno.

En suma, el loable objetivo normativo de procurar que las reglas de buen gobierno alcancen a todos los que integran la cúpula de las organizaciones públicas enturbia, sin embargo, la distinta naturaleza de la relación jurídica que mantienen los altos cargos con sus respectivas instituciones.

Sea como sea, y fuera de las cuestiones que suscita la integración legal automática de los miembros del Gobierno dentro de la AGE, resulta que la utilización de la noción de alto cargo a los efectos de la aplicación del código de buen gobierno previsto en la LTBG, no tiene tampoco en cuenta las notables diferencias que existen -bajo esta rúbrica común- entre los diferentes responsables de las Administraciones públicas ${ }^{22}$. Muy seguramente, esta situación se debe al éxito y generalización del sistema de confianza política en el acceso a las funciones y cargos públicos en nuestro sistema jurídico. Sistema de confianza patrocinado por la llamada nueva gestión pública, paradigma de la reforma administrativa que durante los años noventa del pasado siglo sostenía como idea fuerza «que los ciudadanos, a través de sus representantes políticos, retomen el control del Estado, desplazado impropiamente a las manos de los burócratas y de los grupos de interés» (Prats Catalá, 2004, p. 66); idea, en su día, especialmente atractiva para el caso español si se tiene en cuenta que en el marco de la elaboración de la CE una parte de la literatura especializada coincidió en denunciar «la apropiación de las decisiones políticas por los altos cuerpos de la Administración» (Ortega, 2010, p. 13), pero que, de acuerdo con la doctrina (Santamaría, 1988, p. 82; Morell, 1994, y Castillo, 2010), suscita también muy serias

${ }^{21}$ El artículo 25 LTBG es del siguiente tenor: «1. En el ámbito de la Administración General del Estado las disposiciones de este Título se aplicarán a los miembros del Gobierno, a los Secretarios de Estado y al resto de los altos cargos de la Administración General del Estado y de las entidades del sector público estatal, de derecho público o privado, vinculadas o dependientes de aquella. A estos efectos, se considerarán altos cargos los que tengan tal consideración en aplicación de la normativa en materia de conflictos de intereses. 2. Este Título será de aplicación a los altos cargos o asimilados que, de acuerdo con la normativa autonómica o local que sea de aplicación, tengan tal consideración, incluidos los miembros de las Juntas de Gobierno de las Entidades Locales. 3. La aplicación a los sujetos mencionados en los apartados anteriores de las disposiciones contenidas en este Título no afectará, en ningún caso, a la condición de cargo electo que pudieran ostentar».

22 Que van desde el ejercicio de potestades administrativas hasta las tareas de confianza y asesoramiento. 
dudas por la tendencia «desadministravizadora» que conlleva en el acceso y ejercicio de las funciones públicas, conforme a las exigencias del artículo 103.3 CE ${ }^{23}$.

Al respecto, debe notarse, en efecto, que la nota común que todavía abraza a los altos cargos para someterlos a las reglas de buen gobierno previstas en la LTBG y en la LRAC es, como dice para el caso de la Administración general-estatal el artículo 1.2.g) de la LRAC, la formal de que su «nombramiento se efectúe por el Consejo de Ministros» (Carro, 2010, p. 28). Esto es, que tales cargos respondan, como digo, a un modelo o sistema de estricta relación de confianza política derivado del artículo $23 \mathrm{CE}$, donde, como bien dice la doctrina, «la confianza que se deposita en quien se elige o designa para un cargo de esta índole está presente en la regulación del inicio, contenido y extinción de la relación» (Morell, 1994, p. 32, la cursiva en el original). Por ello y, en lo que ahora importa destacar, fuera de esa relación de confianza no ha existido, con carácter general, un estatuto personal común de los derechos y deberes de los altos cargos y, consecuentemente, el cese, que trae causa y se fundamenta en esa misma relación de confianza, corresponde al que elige o designa sobre la base simple del principio del contrarius actus.

Supuesto esto anterior, hay que subrayar que este dato del nombramiento y cese basado en la confianza política -ex artículo $23 \mathrm{CE}-$, que tradicionalmente sirve también para trazar la línea divisoria entre, de un lado, los altos cargos, responsables de las funciones de dirección política de la organización, y, de otra parte, los empleados profesionales encargados de las tareas de ejecución, cuyo acceso a la función pública se cumple de acuerdo a los principios de mérito y capacidad -ex artículo 103.3 CE- (Fuentaja, 2013 y Fernández, 2013), no se revela del todo útil a los efectos de la aplicación del código de buen gobierno establecido por la LTBG. Vale decir, en efecto, que la sola y exclusiva relación de confianza que caracteriza inicialmente a los altos cargos, suscita una necesaria reformulación a la luz del código de buen gobierno previsto en la LTBG y desarrollado en la LRAC.

De entrada, y aunque dejemos de lado la problemática ubicación en este cuadro general del llamado personal directivo profesional, introducido por el artículo 13 EBEP $^{24}$, sucede, insisto, que el sistema de confianza política que parece sostener a los altos cargos no tiene la misma naturaleza en todos los casos.

Hay así, en primer lugar, una confianza política originaria aplicable a los cargos públicos que la reciben directamente de los ciudadanos a través de los correspondientes procesos electorales. Este es el caso de los concejales de los ayuntamientos y de quienes corresponde el gobierno y administración de la respectiva entidad local (artículo $140 \mathrm{CE}$ ). Hay, en segundo lugar, una confianza política derivada que alcanza a los cargos públicos que la han recibido, a su vez, de los depositarios de la primera, la llamada originaria. En esta se encuentran, por ejemplo, los alcaldes de los Ayuntamientos (artículo $140 \mathrm{CE}$ ), los miembros del Gobierno de la Nación (artículos 99 y $100 \mathrm{CE}$ ) y los miembros de los Consejos de Gobierno de las Comunidades Autónomas (artículo 152). Y, en fin, cabe hablar, además, de una confianza política objeto de matización y de cierto control en el caso del nombramiento de determinados cargos públicos mediante la comparecencia previa ante el Congreso de los Diputados (Blanco Valdés, 1996-1997) de las personas elegidas por el Gobierno para los organismos reguladores o, también, para ser nombrado Presidente de Consejo de Estado ${ }^{25}$.

\footnotetext{
${ }^{23}$ Tendencia que según algún autor conduce a su degeneración (Parada, 1999).

${ }^{24}$ Sobre dicha figura véase: Ortega y Maeso (2010) y Moreu [et al.] (2012).

${ }^{25}$ Según la disposición adicional tercera de la LRAC, este procedimiento de comparecencia previa será seguido en relación con los nombramientos de las personas que vayan a ser designadas Presidente del
} 
Pero, además, fuera ya de la mencionada estricta confianza, el artículo 2.1 LRAC establece la regla general de que «el nombramiento de los altos cargos se hará entre personas idóneas»; cualidad que se predica sólo de las que reúnen el grado de honorabilidad suficiente y la debida formación y experiencia en la materia. En segundo lugar, en relación con el cese, hay que notar que el principio del contrarius actus se funda en el dato mismo de la pérdida de la confianza otorgada en su momento y, por tanto, no exige ni requiere, en principio, el incumplimiento de ninguna determinada obligación. Dicho de otra manera, el cese, al carecer aquí de toda significación de reproche jurídico, no exige de un procedimiento formalizado más allá de su misma exteriorización (Rodríguez, 2013, p. 315).

En esta línea, es paradigmática la situación de los directores de los gabinetes de la Presidencia del Gobierno, de las Vicepresidencias y de los Ministros, altos cargos de estricta confianza política ex artículos 10 y 16.3 LG, que, en tanto órganos de apoyo político y técnico, realizan tareas de confianza y asesoramiento especial bajo la regla objetiva de que "cesarán automáticamente cuando cese el titular del cargo del que dependen», así como, en su caso, del personal eventual al que igualmente corresponda la condición de alto cargo por razón de su nombramiento por el Consejo de Ministros.

De acuerdo con lo expuesto, el sistema de estricta confianza política que nutre la noción de los altos cargos no es capaz de explicar en estos momentos el estatuto o código de buen gobierno diseñado primero en la LTBG y desarrollado después en la LRAC.

En corto, a mi juicio, esa dificultad se hace especialmente visible en los siguientes puntos: i) el nombramiento de los altos cargos ya no se basa en la estricta relación de confianza cuanto en el cumplimiento de la idoneidad prevista en el artículo 2 de la LRAC; ii) la separación por pérdida de la honorabilidad -artículo 2.1 de la LRAC- y la destitución como sanción disciplinaria, en cuanto medidas principales para lograr «un modelo de ejemplaridad» en la conducta de los responsables públicos, se alejan, igualmente, de la regla del contrarius actus que informa la tradicional remoción libre en el sistema de confianza política y, consiguientemente, iii) la determinación del órgano al que corresponde el ejercicio de esa competencia sancionadora se separa del modelo de confianza política, al no corresponder siempre al que la otorgó con el nombramiento.

Como digo, esas diferencias fundamentales hacen necesaria una breve reflexión sobre la nueva situación que -más allá de la estricta relación de confianzaplantean las reglas de buen gobierno para los altos cargos.

\section{La separación disciplinaria en materia de buen gobierno}

En particular, dentro del régimen jurídico del buen gobierno de los altos cargos, hay que distinguir ahora dos situaciones fundamentales (Bassols, 2015, p. 49):

i) la tradicional derivada de la estricta relación de confianza política, donde rige la regla de la libre remoción por parte de la autoridad que nombra;

\footnotetext{
Consejo de Estado, máximos responsables en los organismos reguladores o de supervisión, así como
} presidentes del Consejo Económico y Social, de la Agencia EFE y de la Agencia de Protección de Datos. 
ii) y la derivada del buen gobierno y sus principios capitales de transparencia, integridad y rendición de cuentas, donde se puede aplicar el derecho disciplinario al margen de la estricta relación de confianza ${ }^{26}$.

La superación de la regla de la estricta confianza política como única técnica para fijar la relación de los titulares de los altos cargos con la organización pública radica, como se ha dicho un poco más arriba, en el colapso producido en el sistema administrativo por su generosa utilización en la provisión de las estructuras administrativas $^{27}$.

La extensión de este criterio junto con los ya mencionados casos de mala gestión y, en definitiva, las escasas consecuencias habidas en la vida política y administrativa para sus responsables, ha conducido a la pérdida de credibilidad de la idea de confianza como regla central del sistema de funcionamiento de las organizaciones públicas (Nettesheim, 2014). La antigua percepción de que la libre separación de los agentes públicos hacía innecesario un derecho disciplinario ha fracasado $^{28}$.

Esta voluntad de atajar la crisis de confianza general sobre la gestión de los asuntos públicos sujetando la acción de los responsables a un severo escrutinio, aparece resaltada en la exposición de motivos de la LTBG de la siguiente manera:

cuando los ciudadanos pueden conocer cómo se toman las decisiones que les afectan, cómo se manejan los fondos públicos o bajo qué criterios actúan nuestras instituciones podremos hablar del inicio de un proceso en el que los poderes públicos comienzan a responder a una sociedad que es crítica, exigente y que demanda participación de los poderes públicos.

Aunque no se diga de manera expresa, el sistema de transparencia y de buen gobierno previsto en la LTBG y en la LRAC es, insisto, una clara respuesta a esa crisis de confianza causada por los abundantes casos de mala gestión, o incluso corrupción, que viene afectando al funcionamiento de las instituciones públicas.

Esa directa relación entre mala gestión, pérdida de confianza y control a través del buen gobierno es, como se viene diciendo, indiscutible en nuestra reciente legislación en la materia, como prueba, insisto, la relevancia otorgada al valor de la integridad personal en la LTBG -la exposición de motivos resalta que las autoridades «deben ser un modelo de ejemplaridad en su conducta»- y, a su vez, en la exigencia de la sociedad de obtener una rápida respuesta a los supuestos de corrupción (Castillo, 2015, p. 146).

Dicho de otra manera, cabe afirmar que el buen gobierno previsto en la LTBG y en la LRAC trata de atajar la crisis de confianza causada por el fraude y la corrupción, mediante el expediente de establecer el código de conducta que significa el régimen de buen gobierno.

\footnotetext{
${ }^{26}$ Circunstancia en absoluto original en nuestro derecho, pues, conforme observa Nieto (1970, p. 48), «la tesis de la compatibilidad de un derecho disciplinario, con la potestad de separación del Príncipe, se confirma plenamente en las instituciones españolas de la monarquía absoluta. En esta época hay cargos que están a la completa disposición real y se encuentran sometidos a un riguroso control formal, en él se expresan las potestades disciplinarias a través de dos figuras: la residencia castellana y la visita»; técnicas a las que nos hemos referido al principio de este escrito.

27 Sobre todo ello véase: Sánchez (2011).

${ }^{28}$ Sobre la emergencia del derecho disciplinario en el momento que el Príncipe pierde la facultad absoluta de separar libremente a sus servidores véase: Nieto (1970).
} 
En suma, desde esta perspectiva general, se comprende entonces que la relación servicio de los altos cargos ya no puede descansar solo en la antigua relación de confianza con la autoridad que lo nombró. El buen gobierno -basado principalmente en la transparencia, integridad y rendición de cuentas- exige un nuevo modelo donde es posible el cese al margen de la confianza y, en particular, una nueva pieza para su cumplimiento: el derecho disciplinario.

Muy seguramente, un sector donde puede percibirse mejor la novedad que aporta el estatuto o código de buen gobierno de la LTBG y la LRAC a la noción tradicional de alto cargo, es el referido a las causas de cese en los denominados organismos reguladores o administraciones independientes.

Como se sabe, el dato de la inamovilidad de sus miembros es una garantía esencial de su independencia orgánica respecto del Poder Ejecutivo y supone, consecuentemente, un necesario alejamiento del modelo de funcionamiento del sistema de confianza política sobre el que descansa la noción de alto cargo entre nosotros. Pero, al mismo tiempo, como ha dicho la doctrina, es necesario que el Gobierno disponga también de alguna posibilidad de cese en casos muy concretos y previa instrucción de expediente, pues esto permite que «no tenga a su libre disposición el cese de los componentes de los organismos reguladores salvo en casos límite y, a la vez, mantenga, aunque de manera muy debilitada, la dirección de la Administración de la que habla el artículo 97 CE» (Vírgala Foruria, 2012, p.93).

De esta manera, y por lo que hace a la CNMC, el artículo 23 de su Ley de creación prevé como causas tasadas de cese en el ejercicio del cargo las siguientes: a) por renuncia aceptada por el Gobierno; b) por expiración del término de su mandato; c) por incompatibilidad sobrevenida; d) por haber sido condenado por delito doloso; e) por incapacidad permanente y, en fin, f) mediante separación acordada por el Gobierno por incumplimiento grave de los deberes de su cargo o el incumplimiento de las obligaciones sobre incompatibilidades, conflictos de interés y del deber de reserva. Dentro de esta última causa tasada de cese, el artículo 2.2 LRAC incluye ahora expresamente su aplicación automática por falta de honorabilidad sobrevenida, «con independencia del régimen sancionador que en su caso pudiera corresponder, previa instrucción de expediente por el titular del Ministerio de Economía y Competitividad» (artículo 23 LCNMC).

Sin duda, esta separación acordada por el Gobierno y la sanción administrativa de destitución, salvo que ya hubieran cesado, prevista tanto en el artículo 30.4 de la LTBG como en el artículo 26.2.a) de la LRAC por la comisión de una infracción muy grave, suscitan un posible riesgo para la independencia de la Comisión respecto del Poder Ejecutivo pero, al mismo tiempo, acredita que las reglas de integridad del buen gobierno tienen una clara vocación ordenadora de las autoridades públicas, más allá de la estricta relación de confianza y de la autonomía o independencia de determinadas organizaciones.

En suma, vale decir que la relación entre «confianza» y "observancia de las reglas de buen gobierno», deriva de que la segunda alude a requisitos para el acceso y desempeño del cargo para el que se haya sido nombrado, mientras que la primera atiende al vínculo entre el que designa y el designado. Consecuentemente, el cese por razón de confianza y el derivado del incumplimiento del código de comportamiento son diferentes. Así lo demuestra el caso de las administraciones independientes, pues, en ellas, no hay estricta relación de confianza (esta última solo puede y debe darse allí donde la tarea que comparten el que designa y el designado tenga un contenido político no estrictamente administrativo; pero lo político incluye, como se sabe, la dirección de la Administración ex art. $97 \mathrm{CE}$ ). 
Supuesto todo lo anterior y, como ha señalado la doctrina (Bassols, 2015, p. 49 y Castillo, 2015, p. 153), cuestión enteramente diferente del derecho disciplinario establecido en la LTBG, es la conveniencia de utilizar para la tipificación de las infracciones de buen gobierno una tipología muy próxima a la empleada para los funcionarios públicos. Procede anotar en este punto la escasa innovación de la LTBG, pues ocurre que las muy graves contenidas en el artículo 29 LTBG no son otra cosa que una mera repetición de las infracciones también muy graves ordenadas antes en el artículo 95.2 del EBEP.

Esta operación de la LTBG de configurar una buena parte del código de buen gobierno de los responsables públicos sobre la base aplicar una serie de infracciones ya previamente establecidas para los empleados públicos, suscita la duda acerca de la corrección de tal opción, pues, como dice la doctrina, «Gobierno y Administración son instituciones distintas y también lo son la ética del político y la del funcionario profesional» (Irurzun, 2010, p. 82).

Por muy similares razones, tampoco resulta pacífica la opinión que merece la redacción de las numerosas infracciones disciplinarias contempladas en el artículo 29 LTBG. Con carácter general, puede decirse que pecan de un contenido ciertamente amplio, indeterminado e, incluso, de muy similar factura y, por tanto, susceptible de causar cierta confusión en su correcta interpretación y aplicación. Notable repetición de ideas y conceptos que se traduce, como ha dicho el Consejo de Estado en su dictamen sobre el anteproyecto de la LTBG, núm. 707/2012, de 19 de julio de 2012, en una «cierta inclinación a la utilización de términos abiertos y flexibles, lo que en el caso concreto del régimen sancionador pueden provocar una perniciosa quiebra del principio de tipicidad». Riesgo que aumenta si se tiene en cuenta, como ya muy bien sabemos, que el ámbito subjetivo de aplicación de las infracciones se dirige a un grupo de responsables públicos, los llamados altos cargos y asimilados, que carece de una definición precisa en la propia LTBG.

Sin salir del Derecho disciplinario, debe quizás subrayarse que, si bien es cierto que el cese por pérdida de la confianza en sentido estricto impide, como dicen tanto el artículo 30.4 LTBG como el artículo 26.2.a) de la LRAC, la sanción de destitución por la comisión de una infracción muy grave, nada obsta, en caso de cese, a la debida iniciación, instrucción y resolución del expediente disciplinario de buen gobierno para la aplicación, en su caso, de las demás sanciones previstas en dichas normas. Y, desde luego, conforme tanto al artículo 30.6 y 7 de la LTBG como al artículo 26.3 de la LRAC y al artículo 36.1 de la LRJSP, todo ello sin perjuicio de la posible exigencia de responsabilidad penal o patrimonial al alto cargo por la conducta realizada ${ }^{29}$.

De resto, y como ha señalado también la doctrina (Bassols, 2015, p. 55), sería conveniente que el derecho disciplinario de buen gobierno fuera competencia de una autoridad distinta a la que ejerce el control último de la confianza política en el marco de la Administración General del Estado ${ }^{30}$. Autoridad que podría radicar, desde luego, en el Consejo de Transparencia y Buen Gobierno y salvaría, muy seguramente, la dificultad de poner en marcha un expediente disciplinario sobre un cargo de confianza ya que, de incoarse, podría poner en duda al órgano que la confirió en su momento.

\footnotetext{
${ }^{29}$ Sobre el tema de la responsabilidad de las autoridades y del personal de las Administraciones públicas véase: Nieto (2008) y Doménech Pascual (2008).

30 Tanto el artículo 31 LTBG como el 27 LRAC atribuyen la competencia en materia disciplinaria de buen gobierno bien al Consejo de Ministros, bien al Ministro de Hacienda y Administraciones Públicas.
} 


\section{Conclusiones}

Sobre la base de todo lo expuesto es posible terminar con las siguientes breves conclusiones.

Por de pronto, cabe afirmar que la lucha contra las malas prácticas detectadas en el interior de las organizaciones públicas nutre y da sentido a la actual idea del buen gobierno en nuestro derecho, al centrarse, tanto en la LTBG como en la LRAC, en un régimen jurídico dibujado por un conjunto de principios generales y de actuación aplicable a los miembros del Gobierno, a los altos cargos de la Administración General, así como a otras autoridades públicas asimiladas a las anteriores de las Comunidades Autónomas y de las Entidades Locales en virtud de la LTBG.

El buen gobierno se cifra, por tanto, en un régimen referido sólo a las personas que ocupan los altos cargos de dirección de las organizaciones públicas y se concreta, principalmente, en un derecho disciplinario -inspirado en su interpretación y aplicación por esos principios generales y de actuación- al que se suma luego un doble régimen sancionador dedicado, uno, a la gestión económico-presupuestaria y, otro, a los conflictos de intereses en que pueden incurrir dichos responsables públicos. En lo que aquí interesa, este concreto régimen sancionador en materia de conflictos de intereses y de incompatibilidades se remite a la vigente LRAC.

Esta decisión del legislador estatal nacional de identificar el buen gobierno con un código de conducta para los dirigentes públicos de naturaleza esencialmente sancionadora, supone adoptar una interpretación reducida dentro de los posibles significados que rodean hoy a la noción de buen gobierno.

Así las cosas, el buen gobierno previsto en la legislación nacional establece las reglas de la relación de servicios que une a la persona física (titular o no del órgano) con la correspondiente Administración Pública y determina, por tanto, su integración en el derecho de la organización al hacer operativos y aplicables una serie de principios centrales en todas las Administraciones públicas, a saber: la transparencia, la integridad y la rendición de cuentas.

Por consiguiente y, de acuerdo con todo lo anterior, puede decirse que no se asume por el legislador el reto de establecer un completo estatuto de los responsables públicos donde, junto al régimen de acceso, permanencia y cese en el cargo, haya un sistema de derechos y obligaciones que detalle, por ejemplo, el sistema de retribución, el contenido y evaluación del desempeño, así como la rendición de cuentas; aspectos muy unidos, por cierto, al principio de transparencia. Pues, en efecto, cabe advertir que una parte considerable del buen gobierno entendido en sentido amplio se refiere precisamente a la transparencia en todo lo relativo al ejercicio responsable de la actividad pública.

\section{Bibliografía}

Bassols Coma, M. (2015). Buen gobierno, ética pública y altos cargos. Revista española de derecho administrativo (172), pp. 27-60.

Bermejo Latre, J. L. (2008). La Administración y el derecho al honor. Revista de administración pública (175), pp. 375-398.

Blanco Valdés, R. (1996-1997). Acción de gobierno, política de nombramientos y control parlamentario. Documentación Administrativa (246-247), pp. 145-189.

Bustos Gisbert, R. (2016). Las reglas de conducta de los políticos: evolución en el 
Reino Unido. Revista Vasca de Administración Pública (104-II), pp. 267-292.

Carrillo Donaire, J. A. (2010). Buena administración, ¿un principio, un mandato o un derecho subjetivo? En J. A. Santamaría. (dir.), Los principios jurídicos del Derecho administrativo (pp. 1137-1165). Madrid, España: La Ley.

Carro Fernández-Valmayor, J. L. (2010). Ética pública y normativa administrativa. Revista de Administración Pública (181), pp. 9-37.

Castillo Blanco, F. (2010). El sistema de la confianza política como modelo de la función directiva local. En A. L. Ruiz. (coord.), El gobierno local. Estudios en homenaje al Profesor Luis Morell Ocaña (pp. 493-530). Madrid, España: lustel.

Castillo Blanco, F. (2015). Garantías del derecho ciudadano al buen gobierno y a la buena administración. Revista Española de Derecho Administrativo (172), pp. 123-162.

Elliot, J. H. (2012). Haciendo historia. Madrid, España: Taurus.

Doménech Pascual, G. (2008). Por qué la Administración nunca ejerce la acción de regreso contra el personal a su servicio. InDret (2/2008).

Fernández Farreres, G. (2007). Los códigos de buen gobierno de las administraciones públicas. Administración\&Cidadania, vol. 2 (2).

Fernández Ramos, S. (2013). Los falsos empleados públicos: el personal eventual. Revista General de Derecho Administrativo (34), pp. 1-37.

Fernández Ramos, S. y Pérez Monguió, J.M. (2020). Transparencia y buen gobierno. Revista General de Derecho Administrativo (53).

Fuentaja Pastor, J. A. (2013). Pasado, presente y fututo de la función pública. Madrid, España: Civitas\&Thomson.

García de Enterría, E. (1985). La organización y sus agentes: revisión de estructuras. En La Administración española, $4^{a}$ edición. Madrid, España: Alianza.

García-Pelayo, M. (2009). El buen y el mal gobierno, Obras completas, II. Madrid, España: CEPC.

Garriga, C. (1991). Control y disciplina de los oficiales públicos en Castilla: la «visita» del Ordenamiento de Toledo (1480). Anuario de Historia del Derecho Español (61), pp. 215-390.

Gimeno Feliu, J. M. (2019). Corrupción y seguridad jurídica. La necesidad de un marco normativo de las decisiones públicas anclado en los principios de integridad y de transparencia. RITI (9).

González Alonso, B. (1978). El juicio de residencia en Castilla. I: Origen y evolución hasta 1480. Anuario de Historia del Derecho Español (48), pp. 193-248.

González Alonso, B. (2000). Los procedimientos de control y exigencia de responsabilidad de los oficiales regios en el Antiguo Régimen (Corona de Castilla, siglos XIII-XVIII). Anuario de la Facultad de Derecho de la Universidad Autónoma de Madrid (4), pp. 249-272.

Iglesias, F. (2007). Urbanismo y democracia. Alternativas para evitar la corrupción. Madrid, España: Fundación Alternativas.

Irurzun Montoro, F. (2010). Ética y responsabilidad en la Administración pública. Revista Documentación Administrativa (286-287), pp. 79-111.

Jiménez Asencio, R. (1998). Altos cargos y directivos públicos (2da edición). Oñati, España: Instituto Vasco de Administración Pública.

Martín-Retortillo, L. (1993). Honorabilidad y buena conducta como requisitos para el ejercicio de profesiones y actividades. Revista de Administración Pública (130), pp. 23-96.

Martín-Retortillo, L. (1997). Reflexiones de urgencia sobre el informe Nolan. Revista Aragonesa de Administración Pública (11), pp. 149-164.

Menéndez Rexach, A. (2008). El fomento de las buenas prácticas administrativas en la nueva Ley de suelo y otras normas estatales recientes. Anuario de la Facultad de Derecho de la Universidad Autónoma de Madrid (12), pp. 542-590.

Morell Ocaña, L. (1994). El sistema de confianza política en la Administración pública. Madrid, España: Civitas. 
Moreu Carbonell, E. [et al.] (2012). La función directiva. Revista catalana de dret públic (45), pp. 76-93.

Nettesheim, N. (2014). Confianza y «gobernanza» democrática. La confianza como presupuesto de legítima "gobernanza» democrática europea. Revista de Estudios Políticos (165), pp. 95-115.

Nieto, A. (1960). Fuentes legislativas preconstitucionales para la historia de la burocracia en España. Revista de Administración Pública (33), pp. 273-304.

Nieto, A. (1970). Problemas capitales del Derecho disciplinario. Revista de Administración Pública (63), pp. 39-84.

Nieto, A. (1984). Los estudios sobre la Administración pública: la necesidad de construir una disciplina que sea la base formativa de una clase directiva profesionalizada. Revista Documentación Administrativa (200), pp. 7-42.

Nieto, A. (1997). Corrupción en la España democrática. Barcelona, España: Ariel.

Nieto, A. (2008). Responsabilidad personal y responsabilidad del Estado. Intervención en la sesión del día 22 de abril de 2008 en la Real Academia de Ciencias Morales y Políticas. Madrid, España.

Ortega Álvarez, L. (2010). Prólogo a la obra colectiva La alta dirección pública: análisis y propuestas. Madrid, España: Instituto Nacional de Administración Pública.

Ortega Álvarez. L. y Maeso Seco, L. F. (coords.) (2010). La alta dirección pública: análisis y propuestas. Madrid, España: Instituto Nacional de Administración Pública.

Parada Vázquez, R. (1999). La degeneración del modelo de función pública. Revista de Administración Pública (150), pp. 413-452.

Parejo Alfonso, L. (2007). La contribución de la Ley 8/2007, de Suelo, al remedio del arbitrismo urbanístico y su secuela de corrupción. Cuadernos de Derecho Público (31), pp. 51-78.

Parejo Alfonso, L. (2013). Urbanismo y corrupción: un problema no solo de legalidad. Temas para el Debate (223), pp. 35-41.

Parejo Alfonso, L. (2016). La vigilancia y la supervisión administrativa. Valencia, España: Tirant lo Blanch.

Ponce Solé, J. (2012). La prevención de la corrupción mediante la garantía del derecho a un buen gobierno y a una buena administración en el ámbito local. Anuario del Gobierno Local, pp. 93-140.

Ponce Solé, J. (2019). La lucha por el buen gobierno y el derecho a una buena administración mediante el estándar jurídico de diligencia debida. Cuadernos Democracia y Derechos Humanos.

Prats Catalá, J. (2004). Las transformaciones de la Administraciones públicas de nuestro tiempo. En F. Sainz. (Ed.), Estudios para la reforma de la Administración pública, Instituto Nacional de Administración Pública (pp. 27-102). Madrid, España: editorial.

Quintás Seoane, J. R. (2012). Supervisando al supervisor bancario: riesgos y estrategias de cobertura. Barcelona, España: Publicaciones de la Real Academia de Ciencias Económicas y Financieras.

Ramió, C. (2016). La renovación de la función pública. Madrid, España: Catarata.

Rivero Ortega, R. (2012). La necesaria innovación en las instituciones administrativas. Madrid, España: Instituto Nacional de Administración Pública.

Rodríguez Escanciano, S. (2013). Despidos y otras medidas de (re)estructuración de plantillas laborales en el sector público. Madrid, España: lustel.

Sánchez Morón, M. (2011). Sobre la captura del empleo público. Revista Vasca de Gestión de Personas y Organizaciones Públicas (1), pp. 71-79.

Santamaría Pastor, J. A. (1984). La teoría del órgano en el Derecho administrativo. REDA, núm. 40/41.

Santamaría Pastor, J. A. (1988), Gobierno y Administración: una reflexión preliminar, Revista Documentación Administrativa, (215), pp. 67-84.

Villoria, M. (2012). Transparencia y valor de la transparencia. Marco conceptual. 
Publicación digital 2/2012, Fundación Democracia y Gobierno Local. Recuperado de https://www.gobiernolocal.org/docs/publicaciones/Transparencia_ponencias2.pdf

Villoria M. y Izquierdo Sánchez, A. (2016). Ética pública y buen gobierno. Regenerando la democracia y luchando contra la corrupción desde el servicio público. Madrid, España: Tecnos.

Villoria Mendieta, M.; Gimeno, J. M. y Tejedor J. (2016). La corrupción en España. Ámbitos, causas y remedios jurídicos. Barcelona, España: Atelier.

Vírgala Foruria, E. (2012). Los organismos reguladores en la crisis económica: su reformulación en la ley de economía sostenible. Revista Española de Derecho Constitucional (94), pp. 61-115.

Zambonino Pulito, M. (2019). Buen Gobierno y buena administración. Madrid, España: lustel. 